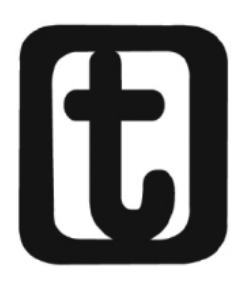

\title{
O MITO DO DESENVOLVIMENTO SOCIOECONÔMICO DO BRASIL NO SÉCULO XXI: ANÁLISE A PARTIR DOS PLANOS GOVERNAMENTAIS DA ERA LULA ${ }^{1}$
}

\author{
The myth of socioeconomic development in Brazil in 21st Century: \\ analysis from Lula's Government Plans
}

\section{Mirella Rocha}

\section{RESUMO}

Este artigo tem como objetivo referenciar o Brasil na conjuntura latino-americana do século XXI com o intuito de analisar o conteúdo do desenvolvimento socioeconômico em curso. Em nossa hipótese, na esteira dos que indicam que o novo século inaugurou, na América Morena, a reedição da conhecida fórmula do desenvolvimentismo - por meio do chamado novo-desenvolvimentismo, com sua agenda de desenvolvimento socioeconômico inaugurada no Brasil com o governo do Partido dos Trabalhadores - obscurece as contradições típicas do capitalismo dependente constituindo-se em um mito. O projeto em curso pode produzir a expansão efêmera da economia, porém sem as rupturas com a matriz oligárquica que marcam as sociedades periféricas, com seus sistemas de privi-

\footnotetext{
${ }^{1}$ Este artigo é parte das análises desenvolvidas na dissertação de Mestrado, bem como nos estudos realizados junto ao Grupo de Pesquisa Trabalho e Política Social na América Latina, vinculado ao Instituto de Estudos Latino-Americanos da Universidade Federal de Santa Catarina (IELA/UFSC). Trata-se da versão revista e ampliada do texto Paradoxos do desenvolvimento socioeconômico no Brasil do século XXI, escrito em coautoria com a Prof. Dra. Beatriz Paiva e apresentado na modalidade Comunicação Oral na CODE-IPEA/2011.

${ }^{2}$ Doutoranda da Escola de Serviço Social da Universidade Federal do Rio de Janeiro (ESS/UFRJ) e pesquisadora junto ao Instituto de Estudos Latino-Americanos da Universidade Federal de Santa Catarina (IELA/UFSC). E-mail: <mirellafr@gmail.com>.
} 
légios e de poder antipopular, com sua ossatura histórica assentada na superexploração da força de trabalho. Além disso, é objetivo fundamental deste artigo retomar o legado teórico-político da Teoria Marxista da Dependência, como importante percurso intelectivo para as nossas reflexões e formulações desde a América Latina.

\section{PALAVRAS-CHAVE}

Novo-Desenvolvimentismo. Brasil. Governo Lula. Teoria Marxista da Dependência.

\section{ABSTRACT}

This article aims to contextualize Brazil's situation in Latin America in the 21st Century in order to analyze the content of the ongoing socio-economic development. Following those who claim that a new century was started in América Morena, our hypothesis is that reissuing a well-known formula of developmentalism - the so-called new-developmentalism, with its agenda of socioeconomic development inaugurated in Brazil with the Worker's Party government - has obscured the typical contradictions of dependent capitalism, which has become a myth. The ongoing project can produce an ephemeral expansion of the economy, but it does not really disrupt the oligarchic matrix that marks the peripheral societies and their systems of privilege and unpopular power, and its longtime history of overexploitation of the work force. Moreover, one of the fundamental purposes of this article is to resume the theoretical and political legacy of the Marxist Theory of Dependency, as an important intellectual resource for our reflections and formulations for Latin America.

\section{KEYWORDS}

New-Developmentalism. Brazil. Lula's Government. Marxist Theory of Dependency.

Submetido: 30/3/2012

Aceito: 6/5/2012

\section{INTRODUÇÃO}

É sabido que o capitalismo é marcado por uma sucessão de crises cíclicas e estruturais, que se manifestam devido às contradições imanentes deste modo de produção que é, em sua essência, antagônico. Num tempo já dilatado, desde os últimos anos da década de 1970, e numa escala global, vivencia-se mais uma onda da crise cíclica e estrutural do capitalismo, agora intensificada pelo padrão 
de acumulação dado pela financeirização, ou seja, ainda mais antagônico se considerarmos as determinações históricas e geopolíticas do imperialismo que afetam duramente os países periféricos.

O processo referenciado como globalização da economia, para além do alardeado discurso da globalização da informação e do conhecimento técnico-científico, remete às sucessivas ondas de modernização capitalista, cujos efeitos principais traduzem-se em agudização das condições de reprodução social da classe trabalhadora.

Na América Latina, os efeitos dessa processualidade costumam ser mais graves. Aqui os trabalhadores historicamente são submetidos aos mais perversos mecanismos de superexploração da força de trabalho e de invisibilidade política e social, e do ponto de vista dos seus direitos apenas alcançam frágeis aportes de proteção social pública. Algumas medidas que costumeiramente fazem parte desse processo englobam ajuste econômico, mecanismos de privatização, terceirização, ondas de desemprego, aumento dos postos de trabalho informal, pauperização e perda de direitos sociais conquistados a duras penas.

Esse foi o roteiro da grande maioria dos países latino-americanos entre as décadas de 1980 e 1990, período em que o neoliberalismo varreu o continente. Todavia, ao que indica boa parte das análises sobre a conjuntura socioeconômica e política da região, aquele não é o quadro que se observa no continente a partir do século XXI, sobre o qual muito se proclamou, especialmente em torno da virada à esquerda dos governos da região. ${ }^{3}$

\footnotetext{
${ }^{3}$ Referimo-nos às análises em torno das sucessivas eleições de Hugo Rafael Chávez Frías, na Venezuela, desde 1998; à vitória, no Brasil, de Luis Inácio Lula da Silva, em 2002, e sua posterior reeleição em 2006 e eleição de sua sucessora Dilma Rousseff em 2010; à chegada de Néstor Kirchner à Casa Rosada em 2003 e à continuidade com Cristina Kirchner a partir de 2007; ao triunfo eleitoral da Frente Amplia representada por Tabaré Vázquez, no Uruguai, em 2004 e posterior eleição do ex-guerrilheiro e militante José Mujica; à ascensão de Evo Morales à presidência da Bolívia, em 2006; à ascensão ao poder de Rafael Correa, no Equador, e de Daniel Ortega, na Nicarágua, também em 2006; ainda nesse mesmo ano, à disputa acirrada no Peru, à evidente fraude eleitoral no México e à chamada "Outra campanha" proclamada pelo movimento Zapatista; por fim, e mais recentemente, à eleição de Fernando Lugo, no Paraguai, em 2008, à reeleição de Evo Morales, na Bolívia, em 2009, também nesse ano à vitória do ex-guerrilheiro José Mujica, no Uruguai, à de Dilma Rousseff, no Brasil, em 2010, à reeleição de Cristina Kirchner na Argentina em 2011 e à vitória de Ollanta Humala, no Peru, também em 2011.
} 
Daí, pois, a proposta deste artigo: trata-se de um esforço crítico-dialético para analisar os documentos atinentes ao macroplanejamento de governo do Brasil, no período correspondente aos dois mandatos de Lula da Silva, com o intuito de problematizar alguns nós do projeto de desenvolvimento socioeconômico em curso, especialmente no que se refere ao seu dilatamento para as tarefas necessárias ao campo social e político. Adicionalmente, pretendemos também fazer alguns apontamentos críticos quanto ao Plano de Governo de Dilma Rousseff. Logicamente, não buscaremos aqui a mera exposição de dados históricos e documentais, mas sim o diálogo entre o estudo da expressão desses dados na realidade concreta e a Teoria Marxista da Dependência, importante tradição crítica no estudo do subdesenvolvimento e das relações de produção assentadas na superexploração da força de trabalho.

Dados concretos do desenvolvimento socioeconômico brasileiro evidenciam que, desde o primeiro governo de Lula da Silva, a pobreza diminuiu, o país cresceu, a inserção dos trabalhadores no mercado formal de trabalho aumentou e uma nova classe média formou-se pela expansão do consumo de massa. ${ }^{4} \mathrm{O}$ crescimento do consumo tem uma condicionante que reside na expansão do crédito. O repasse de recursos, provenientes do Tesouro Nacional ou captados no exterior via empréstimos, por parte do Banco Nacional de Desenvolvimento Econômico e Social (BNDES) às empresas, as possibilidades crescentes de financiamento do consumo pelas financeiras de empresas automobilísticas e mesmo a isenção fiscal do Estado pela redução do imposto em determinados setores da produção, como a de linha branca e mesmo a redução do IPI para automóveis, tudo isso tem contribuído para um crescente aumento do consumo de eletrodomésticos e carros. Também a dimensão tomada pelo Programa Minha Casa, Minha Vida tem impulsionado o crescimento do setor da construção civil, a criação de

\footnotetext{
${ }^{4}$ Dados de pesquisa do IPEA, publicados na Folha de São Paulo, em 15 de novembro de 2011 (MAGALHÃES, 2011), indicam que cerca de 6,3 milhões de pessoas deixaram a pobreza extrema no país entre 2004, quando o Programa Bolsa Família foi criado, e 2009. Os mesmos dados indicam que a renda média no país cresceu $28 \%$ (de $\mathrm{R} \$ 495,1$ para $\mathrm{R} \$ \mathbf{6 3 4 , 6}$ ) e o índice de Gini caiu $6 \%$. Além disso, durante o período analisado, a parcela da população brasileira vivendo em famílias com renda mensal igual ou maior do que um salário mínimo per capita subiu de $29 \%$ para $42 \%$, passando de 51,3 a 77,9 milhões de pessoas (RENDA..., 2011).
} 
postos de trabalho nessa área e a compra de unidades domiciliares via financiamento às famílias.

Considerando essas importantes expressões da realidade concreta, bem como o suporte analítico da Teoria Marxista da Dependência, sintetizamos nossas preocupações em uma pergunta inicial, que nos guiará no decorrer deste artigo: o alardeado desenvolvimento socioeconômico da Era Lula tem levado à superação dos limites estruturais que a acumulação dependente imputa às classes trabalhadoras? Uma resposta positiva a essa questão nos levaria a um tipo diferente de desenvolvimento capitalista, assentado no crescimento econômico e na distribuição de renda. Uma resposta negativa, pelo contrário, evidenciaria o caráter efêmero da programática desenvolvimentista atual e nos permitiria, por sua vez, observar limites nesse tipo de política econômica e social. Àquela pergunta inicial, portanto, coloca-se outra: de qual das duas vias o tipo particular de desenvolvimento capitalista no Brasil nos últimos anos está mais próxima?

Em nossa hipótese, na esteira dos que indicam que o novo século inaugurou, na América Morena, a reedição da conhecida fórmula do desenvolvimentismo - por meio do chamado novo-desenvolvimentismo, com sua agenda de desenvolvimento socioeconômico inaugurada no Brasil com o governo do Partido dos Trabalhadores - obscurece as contradições típicas do capitalismo dependente. $O$ projeto em curso pode produzir a expansão efêmera da economia, porém sem as rupturas com a matriz oligárquica que marcam as sociedades periféricas, com seus sistemas de privilégios e de poder antipopular, com sua ossatura histórica assentada na superexploração da força de trabalho.

Duas observações metodológicas cabem aqui.

A primeira com respeito aos documentos analisados: tratam-se dos Planos Plurianuais (PPA) do governo Lula: o PPA 2004-2007 - Plano Brasil de Todos e o PPA 2008-2011 - Desenvolvimento com inclusão social e educação com qualidade, em virtude de o PPA constituir o principal instrumento de planejamento da gestão pública no Brasil, no qual são definidas as diretrizes estratégicas, metas e prioridades de desenvolvimento econômico e social do país. 
A segunda com respeito à mirada a partir do campo das políticas sociais, motivada pelo campo de conhecimento e de investigação que tem mobilizado os pesquisadores da área do Serviço Social, no seu esforço em se apropriar criticamente dos determinantes estruturais das políticas sociais no capitalismo monopolista. Nesse sentido, reconhecemos que a agenda da Associação Brasileira de Ensino e Pesquisa em Serviço Social (ABEPSS) é bastante fecunda, pois é emergente pensar criticamente o projeto de desenvolvimento socioeconômico brasileiro em curso sob a insígnia do desenvolvimentismo, com o objetivo de trabalharmos com mais propriedade os argumentos técnico-políticos atinentes às inevitáveis disputas que se processam nesse cenário.

\section{NOTAS CRÍTICAS SOBRE O DESENVOLVIMENTISMO BRASILEIRO INSCRITO NOS PLANOS DE GOVERNO DA ERA LULA}

O caminho percorrido em direção à resposta às indagações anteriormente referenciadas nos aponta uma questão metodológica importante. Não podemos partir da teoria e depois traçar uma tentativa de enquadrar a realidade nela sob constantes concessões e simplificações do real. Caio Prado Jr. (1966), em A Revolução Brasileira, denuncia que tal expediente tornou-se prática corriqueira na análise da realidade promovida pelo marxismo coIonizado pelos manuais soviéticos da década de 1950. Caio Prado refere-se, sobretudo, ao Partido Comunista Brasileiro (PCB) de seu tempo, mas não podemos negar aqui que tal vício se difundiu bastante para caracterizarmo-lo por meio de apenas um exemplo. O que nos importa ter em mente aqui é que a crítica devastadora de Caio Prado ao apriorismo metodológico, que partia da realidade ao fato concreto e promovia, assim, uma "teorização às avessas", reforçou uma tendência crítica e autônoma intelectualmente dentro do próprio partidão. Correntes contrárias a esta forma de análise (a qual consequentemente promovia uma ação política também desencontrada em relação à realidade) começaram a questionar postulados supremos como a presença de resquícios feudais no Brasil e a dualidade entre uma burguesia comercial ou compradora e uma burguesia nacional ou desenvolvimentista. Eram postulados básicos da análise do $\mathrm{PCB}$, mas não correspondiam necessariamente a uma realidade que já era capitalista desde o momento mesmo de sua integração ao mercado 
mundial. Na essência de sua suposta fachada feudal, o sistema colonial cumpria uma função capitalista à medida que produzia para o mercado, em especial o mercado metropolitano. Assim, o que se identificava como resquícios feudais era justamente a forma específica com que se desenvolveu o capitalismo em nossas paragens, pela via do latifúndio, do trabalho escravo e da exportação de monoculturas. Também a suposta distinção entre uma burguesia comercial e uma burguesia nacional cai por terra quando analisamos que a sobrevivência de ambas no sistema de dominação social que engendram em nosso país depende essencialmente de sua vinculação ao imperialismo e do acesso à tecnologia estrangeira. Historicamente, desenvolveram-se sem o controle básico sobre a massa de mais-valia. Sem o domínio sobre o excedente econômico nacional, já que substancial parte do trabalho nacional era exportada em bens primários e acumulada apenas marginalmente pelas classes dominantes, fizeram-se reféns da estratégia imperialista de dominação, primeiro colonial e depois industrial.

Mas não se reduziu a isso a função cumprida pela América Latina no desenvolvimento do capitalismo: à sua capacidade para criar uma oferta mundial de alimentos, que aparece como condição necessária de sua inserção na economia internacional capitalista, prontamente será agregada a contribuição para a formação de um mercado de matérias-primas industriais, cuja importância cresce em função do mesmo desenvolvimento industrial. O crescimento da classe trabaIhadora nos países centrais e a elevação ainda mais notável de sua produtividade, que resultam do surgimento da grande indústria, levaram a que a massa de matérias-primas voltada para o processo de produção aumentasse em maior proporção. Essa função, que chegará mais tarde a sua plenitude, é também a que se revelará como a mais duradoura para a América Latina, mantendo toda sua importância mesmo depois que a divisão internacional do trabalho tenha alcançado em novo estágio (MARINI, 2005, p. 143-144).

A integração da América Latina ao centro do sistema capitalista mundial veio para deslocar a base da acumulação nos países centrais da mais-valia absoluta à mais-valia relativa, ao passo que "o desen- 
volvimento da produção latino-americana, que permite à região coadjuvar com essa mudança qualitativa nos países centrais, dar-se-á fundamentalmente com base em uma maior exploração do trabalhador" (MARINI, 2005, p. 144). A superexploração da força de trabalho é, portanto, o mecanismo utilizado pelo desenvolvimento capitalista dependente para fazer frente a esta transformação na acumulação de capital dos países centrais. Diminuindo o valor relativo da força de trabalho nesses países, já que opera com a exportação de bens mais intensivos em trabalho e permite a transferência de um valor de que não pode abrir mão o capitalismo central (para operar contra-tendencialmente em relação à diminuição da taxa de lucro), a periferia do sistema requer a elevação do grau de exploração de suas classes trabalhadoras. Trata-se de um mecanismo de defesa contra a estrutura desigual das relações de produção e de troca no sistema mundial: "[...] a atividade produtiva baseia-se sobretudo no uso extensivo e intensivo da força de trabalho: isso permite baixar a composição valor do capital, o que, aliado à intensificação do grau de exploração do trabalho, faz com que se elevem simultaneamente as taxas de mais-valia e de lucro" (MARINI, 2005, p. 156).

A remuneração abaixo do valor de reposição da força de trabalho somente é possível diante de uma verdadeira economia política da submissão completa do trabalho ao capital, com controle sobre o sindicalismo, política salarial de coerção e repressão do Estado contra a organização sociopolítica da classe trabalhadora. Esse ponto é essencial para o entendimento de nosso marco teórico e metodológico, e para avaliarmos as consequências da política de desenvolvimento nos anos do Governo Lula, delineada no primeiro PPA, elaborado no ano de 2003 para o quadriênio 2004-2007. Em nossa reflexão, esse documento - o qual será tomado como observatório mais original da proposta do novo-desenvolvimentismo brasileiro - foi referenciado como a expressão do compromisso no sentido de "promover profundas transformações estruturais na sociedade brasileira” (BRASIL, 2003, p. 3).

Tratava-se de um empreendimento de desenvolvimento econômico e social, a compor um projeto de longo prazo, cuja meta era a inclusão social e desconcentração da renda com crescimento do produto e do emprego. A estratégia visava ao crescimento ambientalmente sustentável, dinamizado pelo mercado de consumo de 
massa, por investimentos e pela elevação da produtividade, bem como à redução da vulnerabilidade externa por meio da expansão de atividades competitivas. As políticas e programas que consubstanciam essa estratégia foram distribuídas em três megaobjetivos: dimensão social; dimensão econômica, regional, ambiental; e dimensão democrática.

O PPA 2004-2007 do governo Lula, nessa direção, trazia a necessidade de planejar o desenvolvimento social aliado ao econômico, ou seja, "[...] construir uma sociedade dinâmica e moderna, tirar o país da letargia, gerar empregos e riquezas e estabelecer justiça social são objetivos que só serão alcançados com um crescimento econômico firme e duradouro" (BRASIL, 2003, p. 13). Nesse diapasão, observa-se que, apesar dos programas sociais serem reconhecidos como absolutamente necessários, são também percebidos como insuficientes "porque o ataque apropriado à exclusão social e à má distribuição da renda exige também crescimento sustentado, com a geração de riqueza em escala suficiente para elevar o volume de investimentos e a massa salarial do país" (BRASIL, 2003, p. 14).

A estratégia medular que o plano apresentava para dar consequência a esse projeto de desenvolvimento no Brasil referia-se à expansão do mercado de consumo de massa, a partir da inserção das famílias trabalhadoras no mercado consumidor das empresas modernas. Segundo o PPA 2004-2007, esse modelo era viável, já que "[...] está inscrito na lógica de operação da economia brasileira" (BRASIL, 2003, p. 17), na qual um aumento do poder aquisitivo das famílias trabalhadoras deveria traduzir-se no aumento da demanda por mercadorias dos ramos de consumo da indústria moderna, o que impulsionaria a demanda por mão de obra. Esperava-se, portanto, o denominado círculo virtuoso, isto é, que a transmissão do aumento da produtividade ao poder aquisitivo das famílias gerasse mais consumo, mais investimentos, mais empregos e assim sucessivamente. A estratégia clássica consistia em investir no setor produtivo-industrial para fomentar o emprego e o aumento da produtividade do trabalho - em que, resumidamente, o trabalhador com maquinário mais sofisticado produz mais no mesmo espaço de tempo - haja vista a diminuição dos preços das mercadorias e o consequente incremento no consumo de massas. Além disso: 
Com os ganhos de produtividade, gera-se o excedente que pode traduzir-se em maiores rendimentos das famílias trabalhadoras, por meio da redução nos preços dos bens e serviços de consumo de massa, da elevação salarial e da elevação da arrecadação fiscal que pode ser destinada a gastos sociais (BRASIL, 2003, p. 17).

No entanto, o PPA 2004-2007 reconhecia que a dinamização da economia, por meio do estímulo ao consumo de massa, imporia políticas adjuvantes a tal estratégia, pois “[...] mesmo em condições de rápido crescimento, tende a haver insuficiente criação de emprego, devido ao fato que os setores modernos são pouco intensivos em mão de obra" (BRASIL, 2003, p. 18). Concorre a esse dado o número elevado de trabalhadores com baixo nível de escolaridade, pouco qualificados ou em situação de desemprego ou subemprego, que dificilmente podem ser absorvidos no ramo industrial.

Por esse motivo, observou-se a necessidade de que o governo federal privilegiasse políticas no sentido de atacar as fragilidades que impediriam o correto funcionamento do círculo virtuoso. É assim que as políticas ditas de inclusão social e de transferência de renda aparecem inseridas na macroestratégia econômica do Plano Brasil de Todos: são indispensáveis ao modelo de desenvolvimento baseado no consumo de massa. As políticas sociais, nesse sentido, constituem importante alavanca ao mecanismo econômico:

As políticas sociais viabilizam o consumo popular ao aumentar o poder aquisitivo das famílias e reduzir a pressão da oferta de mão de obra sobre o mercado de trabalho, favorecendo a transmissão dos aumentos de produtividade aos salários. Por exemplo: a) a reforma agrária e o fomento à agricultura familiar retêm mão de obra no campo e criam renda; b) a exigência de frequência escolar para acesso à política de transferência mantém a criança na escola, reduz o trabalho infantil e melhora a renda familiar; c) a universalização da assistência aos idosos viabiliza seu descanso e libera vagas no mercado de trabalho, além de elevar a renda da família; d) o microcrédito dá suporte ao autoemprego e a postos de trabalho em microempresas, criando emprego e renda; e) os programas de acesso à moradia, infraestrutura e serviços sociais, como saneamento, transporte coletivo, educação e saúde são clássicos geradores de postos 
de trabalho, além de ampliar a renda, ao reduzir gastos como aluguel, remédio e escola; $f$ ) os programas de transferência de renda, a elevação do salário mínimo e o seguro-desemprego operam em favor do modelo de consumo de massa, ao ampliar os rendimentos da família pobre e ao disponibilizar recursos para o aumento dos gastos (BRASIL, 2003, p. 19).

De acordo com o documento, residia aí o grande desafio do país sob coordenação do PPA 2004-2007: eliminar os principais obstáculos ao crescimento continuado da economia, na direção do incremento ao consumo de massa em âmbito interno, bem como a redução da vulnerabilidade externa, considerando a influência positiva de tal redução para a expansão do volume de exportações. A combinação era conhecida: incitar a expansão do consumo bem como a expansão do investimento e das exportações.

É importante referenciar que o crescimento continuado do volume de exportações aparecia como estratégia primordial para a efetividade do PPA 2004-2007, em todos os aspectos. Nesse sentido, estando o desenvolvimento social amarrado ao desenvolvimento econômico e este organicamente vinculado ao dimensionamento das exportações, definia-se a meta do plano: manter o atual dinamismo das exportações do setor agropecuário e, "[...] por meio das economias de escala e ganhos de produtividade, possibilitados pelo aumento do investimento e ampliação do mercado interno, aumentar e diversificar as exportações de manufaturados" (BRASIL, 2003, p. 24).

Há uma perceptível nostalgia do desenvolvimentismo nesse projeto, sem a ousadia do enfrentamento das causas da dependência. Conforme referenciado, a inserção periférica da América Latina no processo de acumulação capitalista em escala global, determinada pela dependência, 5 fundamenta-se a partir da formação de uma divisão internacional do trabalho, que posteriormente acaba por condicionar o desenvolvimento subsequente da região dependente. Em seu ensaio, Dialética da Dependência, Marini (2005) apresenta os mecanismos que determinam a produção e a reprodução de

\footnotetext{
${ }_{5}^{5}$ A dependência, de acordo com análise de Marini (2005), pode ser entendida como uma relação de subordinação que ocorre entre nações formalmente independentes, em cujo marco as relações de produção das nações subordinadas são modificadas ou constantemente recriadas para assegurar a reprodução ampliada dessa condição.
} 
capital em escala ampliada, partindo das relações estabelecidas entre países centrais e países periféricos, e apontando suas consequências sob a organização das sociedades dependentes. Segundo o autor, são estabelecidas relações comerciais que se baseiam em um sistema de trocas desfavoráveis, reatualizando permanentemente os termos do intercâmbio desigual.

Sendo assim, resta aos países latino-americanos exportarem produtos primários, essencialmente gêneros agrícolas e matérias-primas - cujos preços tendem a cair em relação aos produtos industrializados - e importarem tecnologias, equipamentos e maquinarias - de custo indiscutivelmente maior, considerando também o monopólio dos países centrais na produção desses produtos, o que lhes permite vendê-los a um preço mais elevado.

É dessa maneira que os condicionantes da dependência colocam uma maciça transferência de valor produzido na periferia, que é então apropriado no centro da acumulação mundial, de modo que tal dinâmica capitalista é garantida por uma maior exploração da força de trabalho na periferia, por meio da intensificação dos processos de extração de mais-valia. Esse mecanismo configura-se como uma atuação no sentido de produzir ainda mais valor, como resposta dada à depreciação de valor e da produtividade próprias aos países dependentes submetidos ao intercâmbio desigual.

Conforme analisamos, o PPA 2004-2007 apresenta, como motor do desenvolvimento econômico e social, a ampliação na pauta de exportações e o estímulo ao consumo de massa. O documento examinado, portanto, não problematiza e tampouco se propõe a formular respostas aos dilemas da dependência. Isso significa que a histórica impotência do Estado brasileiro e latino-americano, revelada pela submissão aos interesses da economia exportadora de produtos primários, aliada aos que se beneficiam da intensa expropriação da riqueza social pelo mecanismo do endividamento público, seguiu quase intacta, revelando a incapacidade de se romper com esse modelo, reproduzindo e priorizando os mesmos interesses que o fundaram.

Especificamente na chamada "dimensão social”, o PPA 20042007 vincula desenvolvimento econômico referenciado como parte necessária do desenvolvimento social requerido e, além 
disso, apresenta essa histórica relação como uma "inovação" em termos de concepção das políticas sociais.

No que se refere à concepção, a grande diferença reside na integração entre a política social e a política econômica, derivada do modelo de desenvolvimento adotado. $O$ modelo realiza a integração entre, por um lado, a inclusão social e a redistribuição da renda e, por outro, os investimentos e o crescimento da renda e do emprego. A universalização dos direitos sociais básicos e a transmissão dos ganhos de produtividade aos salários estabelecem a sinergia entre as políticas sociais e de investimento, promovendo o crescimento por meio da expansão do mercado de consumo popular (BRASIL, 2003, p. 61).

Nesses moldes, tem-se que os principais desafios assinalados na dimensão social podem ainda ser caracterizados como a tradução de políticas meramente conciliatórias com a ordem econômica vigente, em conformidade exemplar com as orientações dos organismos multilaterais. Tais desafios, bem como as políticas, programas e projetos que os materializariam, retratavam a intenção "[...] do firme compromisso do governo Lula com a inclusão social" (BRASIL, 2003, p. 63). Porém acreditamos que, ao condicionar o que denomina bem estar de todas as famílias brasileiras ao desenvolvimento econômico centrado no aumento do consumo, o PPA 2004-2007 reedita um mito, tal como descrito por Celso Furtado em 1974:

O desenvolvimento econômico, tal como vem sendo praticado pelos países que encabeçaram a revolução industrial, não pode ser universalizado. Mais precisamente: se pretende que o nível de consumo da minoria da humanidade, que atualmente vive nos países altamente industrializados, seja acessível para as grandes massas da população em rápida expansão que formam o chamado terceiro mundo. Esta ideia constitui, com certeza, uma prolongação do mito do progresso, elemento essencial da ideologia reitora da revolução burguesa, dentro da qual nasceu a atual sociedade industrial (FURTADO, 1974, p. 14).

É um mecanismo típico das economias periféricas que o fomento ao crescimento econômico se traduza no aprofundamento das relações de dependência, dessa vez reeditado, seja com au- 
sência do debate das reformas estruturais, seja com a desindustrialização e a expansão do agronegócio, submissos às multinacionais. Nesse sentido, a ideia mitológica do desenvolvimento econômico caracteriza um problema essencialmente político, já que tal empreitada opera pela omissão da dominação dos povos, conforme caracterização de Furtado: “[...] graças a ela tem sido possível desviar a atenção da tarefa básica da identificação das necessidades fundamentais da coletividade e das possibilidades que abre ao homem o progresso da ciência, para concentrá-la em objetivos abstratos como o investimento, as exportações e o crescimento" (FURTADO, 1974, p. 75).

É assim que a alternativa de desenvolvimento econômico e social que remeteria à construção de um novo Brasil, um Brasil de todos, é erigida, pois, a partir de um mito, o que tende a levar à frustração das expectativas daqueles que acreditavam em um governo popular e, pior do que isso, tende a obstruir o real caminho de superação das desigualdades, aquele baseado na satisfação das necessidades das massas, construído a partir de intensa democratização política e econômica da sociedade.

Constituída como alternativa aos males do capitalismo, a virada novo-desenvolvimentista, de acordo com os seus defensores, advoga um Estado capaz de regular a economia, que deve formar um mercado forte e um sistema financeiro funcional, isto é, que seja direcionado para o financiamento da atividade produtiva e não para a atividade especulativa. Para tanto, de acordo com Sicsú, Paula e Michel (2007), é preciso não somente buscar formas inteligentes de ação estatal, complementares à ação privada, como também proporcionar condições para que o Estado possa desempenhar de forma mais eficaz sua ação. Trata-se de adotar uma forma de gestão que aproxime as práticas dos gerentes públicos às dos privados, tornando-os ao mesmo tempo mais autônomos e responsáveis perante a sociedade.

Na crença novo-desenvolvimentista, a concorrência é necessária porque estimula a inovação por parte dos empresários que tentam maximizar o lucro, o que torna o capitalismo dinâmico, impulsionado pelas diferenciações de remunerações e riquezas, desde as habilidades individuais. Há certa ingenuidade ou excesso de otimismo 
nesse vetor. Estes atributos individuais do capitalismo são mistificações, pois as tendências à centralização e à concentração de capital, decifrada por Marx n'O Capital, são obstáculos contundentes à propalada iniciativa dos indivíduos ao desenvolvimento social e econômico de uma nação.

Segundo Sicsú, Paula e Michel (2007), na perspectiva do novo-desenvolvimentismo, o Estado deve ser forte para permitir ao governo a implementação de políticas macroeconômicas defensivas ou expansionistas. Políticas de caráter defensivo são, por exemplo, aquelas que reduzem a sensibilidade do país a crises cambiais; e políticas expansionistas dizem respeito às medidas de promoção do pleno emprego, principalmente em um cenário recessivo. É parte dessa programática, também, as políticas industrial e de comércio exterior, utilizadas de modo estratégico para estimular a competitividade da indústria e melhorar a inserção do país no comércio internacional. O Estado deve, ademais, possuir um sistema tributário progressivo, para reduzir as desigualdades de renda e de riqueza que são exageradas.

Note-se que o desenvolvimento requerido aparece como panaceia.

Com base nos estudos de Marini (2005), sabemos que o capitalismo dependente é uma formação social que acentua, até o limite, as contradições que são próprias ao modo capitalista de produção. Sabe-se, a partir de Marx (1984), que a exploração do trabalhador não é específica das economias periféricas, na medida em que remete ao modo de produção capitalista em si mesmo. No entanto, o que se pretende demonstrar é que "[...] as combinações das formas de exploração capitalista se levam a cabo de maneira desigual no conjunto do sistema, engendrando formações sociais distintas segundo o predomínio de uma forma determinada" (MARINI, 2005, p. 189).

Conforme referenciamos, a superexploração da força de trabalho, mecanismo típico adotado nas economias dependentes, com a intensificação dos processos de extração da mais-valia nas suas formas absoluta e relativa combinadas, segundo análise de Marini (2005), caracteriza-se como um regime de regulação da força de trabalho em que a acumulação de capital repousa sobre a maior exploração do trabalhador e não sobre o aumento da sua capacidade produtiva. 
Assim, de acordo com Marini (2005), o que aparentemente configura um dispositivo estrutural de compensação em nível de mercado caracteriza-se como um instrumento que opera internamente no âmbito das relações sociais de produção, gerando, nos países dependentes, efeitos severos sobre o trabalho, por meio de três mecanismos, quais sejam, "[...] a intensificação do trabalho, a prolongação da jornada de trabalho e a expropriação de parte do trabalho necessário ao operário para repor sua força de trabalho" (MARINI, 2005, p. 156), que caracterizam o modo de produção fundado exclusivamente na maior exploração da força física do trabalhador, em contraposição à exploração resultante do aumento de sua produtividade. Há que se considerar que esses mecanismos impõem condições deploráveis de vida às massas, pois sua manifestação mais expressiva é que a força de trabalho é remunerada muito abaixo do seu valor real, ${ }^{6}$ além da ausência ou precariedade de um sistema de proteção social público.

Importa assinalar ainda que tais tendências tendem a agudizar-se na medida em que as economias latino-americanas desenvolvem-se industrialmente. Isso acontece porque a superexploração do trabalho tende a obstruir o trânsito da produção de mais-valia absoluta à de mais-valia relativa, considerada por Marx (1984) a forma que tende a assumir caráter dominante da relação capital/trabalho no curso de desenvolvimento histórico do capitalismo, conforme assinalado. Segundo análise de Marini (2000), nas economias dependentes, a relação positiva entre o aumento da força produtiva do trabalho e a maior exploração do trabalhador se agrava, pois, à medida que se desenvolve um processo econômico "[...] sobre a base da superexploração, põe-se em marcha um mecanismo

\footnotetext{
${ }^{6}$ Segundo Marini (2005) "[...] importa assinalar que, nos três mecanismos considerados, a característica essencial está dada pelo fato de que são negadas ao trabalhador as condições necessárias para repor o desgaste de sua força de trabalho: nos dois primeiros casos, porque lhe é obrigado um dispêndio de força de trabalho superior ao que deveria proporcionar normalmente, provocando assim seu esgotamento prematuro; no último, porque lhe é retirada inclusive a possibilidade de consumo do estritamente indispensável para conservar sua força de trabalho em estado normal. Em termos capitalistas, estes mecanismos (que ademais podem se apresentar, e normalmente se apresentam, de forma combinada) significam que o trabalho é remunerado abaixo de seu valor, e correspondem, portanto, a uma superexploração do trabalho" (MARINI, 2005, p. 156-157).
} 
monstruoso, cuja perversidade, longe de diminuir, é acentuada ao apelar à economia dependente para o aumento da produtividade, mediante o desenvolvimento tecnológico" (MARINI, 2000, p. 177).

Desse modo, ao que indicam os documentos analisados, o projeto novo-desenvolvimentista não inclui proposições que almejam reformas estruturais: refere-se às medidas que privilegiam a manutenção da ordem econômica e a coesão social. Assim, não contribui somente para jogar água no moinho da decadência ideológica do pensamento burguês, tal como sinalizado por Lukács (1968), mas também para obscurecer as possibilidades revolucionárias de rompimento com os elos fortes do subdesenvolvimento na América Latina, tal como problematizado por Castelo:

O novo-desenvolvimentismo não promove um de-
bate sobre a natureza e as funções do Estado no
modo de produção capitalista, uma avaliação da
fusão dos interesses das classes dominantes em
torno do capital financeiro e da financeirização da
riqueza e dos constrangimentos do mercado mun-
dial à formação de um capitalismo autônomo, isso
sem falar na total ausência das polêmicas sobre as
atuais configurações do mundo do trabalho e no
papel das empresas transnacionais no novo impe-
rialismo (CASTELO, 2010, p. 208-209).

Com essa assertiva não estamos desconsiderando os ganhos reais que os indicadores econômicos e sociais expressam na reprodução social da vida de milhões de brasileiros no período correspondente ao governo Lula, porém as medidas descritas e analisadas estão muito distantes de qualquer opção antineoliberal. Sendo assim, podemos especular se há alguma incompatibilidade entre a agenda do novo-desenvolvimentismo e a neoliberal, de fato.

O PPA brasileiro, relativo ao segundo mandato do governo Lula, elaborado em 2007 para o quadriênio 2008-2011, como já enfatizamos, é expressão da constância e do aprofundamento do modelo já esboçado no primeiro, o PPA 2004-2007. Desse modo, no denominado Plano Desenvolvimento com Inclusão Social de Qualidade, o último do governo de Lula da Silva instituiu as prioridades, em termos de objetivos, programas, projetos e ações para os próximos anos, reafirmando o compromisso com a continuidade do projeto delineado no 
plano anterior, na medida em que as realizações do período anterior foram bem sucedidas, conforme a mensagem presidencial:

Os fundamentos da economia estão sólidos e a confiança na sociedade tem propiciado ambiente favorável aos investimentos privados e à ampliação dos investimentos públicos, com redução contínua da taxa de juros e controle da inflação. As reservas internacionais alcançaram patamar histórico, consolidando a estabilidade econômica (BRASIL, 2007, p. 1).

Considera, pois, que as políticas implementadas no quadriênio anterior lançaram as bases para um desenvolvimento sustentável que finalmente - agora sim - permitirá ao país ingressar no círculo virtuoso, por meio do qual se alcançará em um futuro próximo, a perfeita simetria entre crescimento econômico, redução das desigualdades e respeito ao meio ambiente. Por esse motivo, o novo período de governo seguiu apostando no desenvolvimento econômico para o sucesso das políticas públicas propostas, sentenciando que "a sinergia resultante de tais políticas é, simultaneamente, pressuposto e resultado de uma estratégia de desenvolvimento que opera com base na incorporação progressiva das famílias no mercado consumidor das empresas modernas." (BRASIL, 2007, p. 11). A partir de tal pressuposto, o PPA 2008-2011 organiza as ações do governo em três eixos: crescimento econômico, educação de qualidade e agenda social. Os dois primeiros eixos para serem operacionalizados a partir de dois grandes programas, respectivamente: Programa de Aceleração do Crescimento (PAC) e Plano de Desenvolvimento da Educação (PDE).

Relativo ao PAC, trata-se de um conjunto de investimentos públicos em infraestrutura, principalmente concentrados nos setores de transportes, energia, recursos hídricos, saneamento e habitação, além do que denomina medidas de incentivo ao desenvolvimento econômico, dentre as quais se incluem estímulos ao crédito e ao financiamento, melhoria do ambiente de investimento, desoneração tributária e medidas fiscais de longo prazo. Essas medidas compõem metas fundamentais para a expansão da capacidade produtiva nacional e elevação da produtividade sistêmica da economia e, por esse motivo, prevê o aumento significativo do investimento privado, haja vista que o setor público disponibilizará grande montante de recursos para ampliação do mercado interno. 
O PDE é uma iniciativa do governo federal que tem importante lugar no PPA 2008-2011. Parte da constatação de que “[...] a educação de qualidade representa um objetivo estratégico sem o qual o projeto de desenvolvimento nacional em curso não se viabiliza" (BRASIL, 2007, p. 16) e, nessa esteira, apresenta um plano que, ao reunir um conjunto de iniciativas articuladas ao sistema educativo nacional com a conjugação de esforços dos demais entes federados, tem como prioridade a melhoria da qualidade da educação básica. No entanto, reconhece-se que o investimento na educação básica passa por investimentos também na educação profissional e na educação superior, portanto, todos os níveis de educação aparecem nos programas, organizados em quatro eixos: educação básica, por meio do Programa Compromisso Todos pela Educação, que inclui melhoria da gestão escolar, qualidade de ensino e fluxo; alfabetização e educação continuada, com o Programa Brasil Alfabetizado, cuja meta é reduzir o analfabetismo; ensino profissional e tecnológico no qual está prevista a ampliação; e, ensino superior, com o objetivo de ampliar o acesso ao ensino superior por meio de dois programas principais, o Programa Universidade para Todos (PROUNI) e o Programa de Reestruturação e Expansão das Universidades Federais (REUNI).

No tocante a agenda social, o plano expõe um conjunto de iniciativas prioritárias, cuja ênfase seguiu sendo as transferências condicionadas de renda associadas às ações complementares; o fortalecimento da cidadania e dos direitos humanos; a cultura e a segurança pública. O foco de intervenção dessas políticas também segue sendo a parcela da sociedade mais vulnerável.

Será consolidada uma rede de proteção e promoção social, conjugando ações e programas voltados à garantia dos direitos de cidadania das famílias pobres. A meta é beneficiar o conjunto dos Municípios, dentre eles os mais vulneráveis com a expansão da rede de integração das ações de assistência social, segurança alimentar e nutricional, e transferência de renda, que geram impactos sobre a pobreza, a extrema pobreza e a desigualdade, provocam a dinamização de economias locais e estabelecem a garantia de direitos de cidadania (BRASIL, 2007, p. 14, grifo nosso).

Assim referenciados, os direitos de cidadania parecem se consolidar apenas como identidade assentada em símbolos constitutivos 
de um estilo de vida e de instituições reguladoras acima das desigualdades de classe, servindo exclusivamente ao (sub)desenvolvimento da ordem social capitalista, pois, desse ponto de vista, a ampliação de tais direitos, restritos aos mínimos-mínimos sociais destinado às famílias mais pobres, em consonância com o projeto econômico requerido, configura-se como necessário "[...] à constituição de valores e símbolos que condicionam a lealdade moral e a lealdade política de todos os indivíduos, especialmente dos trabaIhadores, assim integrados à ordem social" (ABREU, 2008, p. 306).

É nessa perspectiva que a agenda social destacava um conjunto de iniciativas que, de forma articulada, deveriam atuar nos territórios de alta vulnerabilidade. As políticas sociais públicas ou em parceria com a esfera privada ou a sociedade civil organizada, no que se refere às políticas setoriais, seguiram como prioridade da agenda social do Governo Lula.

A agenda de implementação do direito socioassistencial, por meio do Sistema Único de Assistência Social (SUAS), aparecia como desafio no âmbito da política de assistência social. Outro desafio mencionado nesse âmbito é a articulação dessa política com as demais políticas sociais. Em especial, segundo o documento, com os principais programas de transferência de renda condicionada, como o Bolsa Família e o Benefício de Prestação Continuada (BPC), e com os serviços e ações desenvolvidas no âmbito da segurança alimentar e nutricional, tendo em vista a urgência na consolidação de "[...] uma rede articulada de promoção e proteção social, voltada às famílias mais vulneráveis" (BRASIL, 2007, p. 115, grifo nosso).

Aqui cabe um importante apontamento analítico: eleger a família como referência para a formulação das políticas sociais denota uma tendência que contribui para reforçar a lógica privatista e psicologizante destas, negligenciando o engendramento de novas e efetivamente democráticas relações intrafamiliares. Os estudos que desenvolvemos nos últimos anos evidenciaram que as ações de proteção social vinculadas ao âmbito privado das relações sociais - a família, o chamado terceiro setor público não estatal e o mercado - tidas como fontes naturais de satisfação das necessidades humanas e sociais, tendem a obscurecer os antagonismos econômicos próprios da sociedade de classes e a capacidade de sua 
superação. Reforça-se, desse modo, o processo de precarização da proteção social como responsabilidade pública, pois a dilatação da esfera privada - seja o mercado, seja a família - desonera a ação governamental (tão propugnada pelas medidas de ajuste fiscal) na mesma medida em que possibilita a reedição dos esquemas controladores junto aos grupos familiares.

Partimos agora para alguns apontamentos sobre o Plano Plurianual para o quadriênio 2012-2015, relativo ao governo de Rousseff, o qual se intitula Plano Mais Brasil. Tal plano, aprovado em janeiro de 2012, materializa a continuidade do projeto de desenvolvimento para o Brasil já colocado nos planos anteriores, a partir da conjugação do crescimento econômico com a melhoria da distribuição de renda e de redução da pobreza.

Assim, o já referenciado círculo virtuoso para a economia brasileira pela via da expansão de rendimentos das famílias e ampliação do consumo de bens e serviços aparece novamente com fôlego no Plano de Governo de Rousseff, o qual se sustenta a partir da aceleração produtiva voltada para o crescimento econômico e da sustentabilidade desse ciclo, baseadas na melhoria das condições de vida da população.

Dessa forma, o modelo de consumo de massa continuará sendo um dos objetivos a serem perseguidos durante o próximo período de governo. Por outro lado, as políticas de transferência de renda, a valorização do salário mínimo aliado à expansão dos postos de trabalho e inclusão produtiva serão perseguidas com o propósito de aprofundar a meta da redução da pobreza extrema no país. Nas palavras do PPA 2012-2015, ressalta-se que

O Brasil que se vislumbra para as próximas décadas já vem sendo construído, sobretudo nos últimos 8 anos: um país que elegeu um projeto de desenvolvimento inclusivo com políticas públicas de transferência de renda, intensificação da extensão e do alcance dos programas sociais e constantes aumentos reais do salário mínimo. Utilizaram-se, ainda, instrumentos de geração de emprego e renda com vistas à ampliação de um mercado de consumo de massa, trazendo maior autonomia ao nosso processo de desenvolvimento com a expansão do mercado interno. [...] Tais políticas nortearam a orientação estratégica para a elaboração do Plano Mais Brasil e permearam a de- 
finição da Visão de Futuro e dos Valores que orientam a ação governamental para os próximos 4 anos. (BRASIL, 2012, p. 15).

[...] O aprofundamento do modelo de consumo e produção de massa será perseguido durante o período de 2012 a 2015. Desta forma, pelo lado da demanda, buscar-se-á o aprofundamento do processo de redução das desigualdades por meio das políticas de transferência de renda, valorização do salário mínimo, expansão dos postos de trabaIho formais e inclusão produtiva. Neste contexto, ganha importância o desafio da erradicação da pobreza extrema com o Plano Brasil Sem Miséria que possibilitará a incorporação de um contingente ainda maior de brasileiros ao mercado interno. Cabe apontar que a estratégia de dinamização do mercado interno deve ainda ser ancorada em uma forma de produção e consumo ambientalmente sustentáveis (BRASIL, 2012, p. 22-23).

Portanto, os desafios postos para o próximo período centram-se no crescimento e estabilidade econômica, na redução das desigualdades, erradicação da pobreza extrema e em potencializar o mercado interno. Soma-se a estes a elevação das fontes de financiamento privadas para os projetos de longo prazo. O destaque nesse plano é aprofundar o mercado de capitais e de crédito, no entanto, não somente por meio de bancos com capital público, como o Banco Nacional de Desenvolvimento Econômico e Social (BNDES), o Banco do Brasil (BB) e a Caixa Econômica Federal (CEF), mas sim potencializando e fomentando fontes privadas de financiamento - processo que possivelmente contribui para o aprofundamento da dependência latino-americana, especialmente no cenário de crise estrutural do capitalismo na idade do capital fictício e da financeirização.

Ainda dentre os desafios para o próximo PPA, está a elevação das taxas de investimento que, segundo os planos do novo governo, viabilizarão a expansão da produção e da geração de emprego, ambos objetivos que consolidarão a perspectiva do desenvolvimento baseado na expansão do consumo e produção de massa, sobretudo no que diz respeito aos investimentos em infraestrutura, tais como nos setores de energia, transporte (rodoviário, ferroviário, portos e aeroportos) e nas condições de armazenagem. 
O desenvolvimentismo em curso está circunscrito ao repertório fisicalista, cuja novidade é tão insólita quanto seu alcance, se considerarmos os objetivos efetivamente negligenciados, àqueles que dizem respeito à terra, ao trabalho, à cultura e à liberdade para as maiorias.

\section{CONCLUSÃO}

Como apontamento conclusivo desta análise, que pretendeu tangenciar aspectos do (sub)desenvolvimento socioeconômico brasileiro, importa destacar que, ao creditar a superação do subdesenvolvimento pela via do desenvolvimento socioeconômico ao crescimento econômico baseado na expansão das exportações e ampliação do consumo de massas, o novo-desenvolvimentismo releva-se um mito, nos termos de Furtado (1974) e limita-se ao desenvolvimento do subdesenvolvimento de Frank (1973).

Sendo assim, os elementos aqui observados não apontam apenas pela evidente preocupação coadjuvante com a chamada "questão social”, mas principalmente pelo obscurecimento das contradições do mundo do trabalho e pelo ocultamento da captura do Estado pelo projeto de dominação e acumulação, dado o discurso harmonizador de interesses distintos e a prática conciliatória no bojo da luta de classes, que sabemos, é linha auxiliar dos mais fortes.

Logo, é possível afirmar que os dois PPA's do Governo Lula e preliminarmente também o PPA do Governo Rousseff expressam, no campo econômico e social, antigas ambiguidades e contradições que, somadas ao legado conservador no âmbito político-democrático no país, comprometem as possibilidades de efetivação de um estatuto político universalista e efetivamente democrático aos direitos sociais nestas latitudes. Ao contrário, o desenho em tela - no encalço do novo-desenvolvimentismo - contribui na manutenção do aprisionamento das medidas de política social como mero mecanismo adjutório ao processo de acumulação de capital, ao passo que opera o obscurecimento dos antagonismos de classe e, em decorrência, a força política contestatória de luta das massas.

Opera-se, mais uma vez, a perda do vínculo de classe da política social, contribuindo para perpetuar uma lógica contrária ao universo ético-político libertário e igualitário. Sem responder as ambiguidades, é possível visualizar no desenho do campo político e social 
do país um futuro que ao repetir o passado, tende a expressar um museu de grandes novidades.?

A mutilação das funções do Estado latino-americano frente aos compromissos sociais básicos (como universalizar a seguridade social e a educação de qualidade e gratuita) é o espelho narcísico da impotência do Estado brasileiro, cujo reflexo encobre a sua submissão aos interesses da economia exportadora de produtos primários, aliada aos que se beneficiam da intensa expropriação da riqueza social pelo mecanismo do endividamento público. A regra da dependência, que expressa a incapacidade de romper com esse modelo, ao que parece, é a mesma na recessão, no desenvolvimentismo ou na sua versão coetânea do século XXI.

É assim que a modernização capitalista no Brasil e no conjunto da América Latina encontra o século XXI num mesmo pêndulo: intensificação brutal da concentração da renda, riqueza e propriedade, ao lado da privatização contínua do poder político e do encastelamento dos esquemas ideológicos especialmente reeditados, desde as duas últimas décadas do final do século XX. O novo ciclo de dependência e de acumulação latino-americana delineia as estratégias de superendividamento do Estado e de austeridade fiscal, entendida como contenção dos gastos sociais referentes aos direitos das classes trabalhadoras nacionais. Ademais, esse diapasão de medidas revela-se profundamente autoritário e antipopular, embora encoberto pelo manto da democracia representativa, o suficiente para esterilizar a luta de classes em patamares de mera resistência às perdas, numa contínua debilitação e subalternização do protagonismo das massas populares.

Esse ponto é primordial na interlocução com o projeto ético-político do Serviço Social, pois a ruptura com a lógica desabilitadora do caráter protagônico das massas, na direção de um projeto democrático-radical consubstanciado no compromisso ético-político da profissão, deve comandar a investigação do pesquisador-assistente social, contribuindo para ultrapassagem dos mecanismos de desmobilização e de subalternização, que descredenciam as estratégias de fortalecimento político da população. Nesse sentido, ao

7 Em alusão à música de Cazuza, O tempo não para (1995). Disponível em: <http:// letras.mus.br/cazuza/45005/>. 
refletir acerca do cenário atual e de suas determinações na América Latina, na condição de assistente social, cumpre-nos desvendar a configuração atual do processo de desenvolvimento capitalista e a agudização de suas contradições nos países dependentes, no intuito de retomar o horizonte ético-político que referencia a democracia e a liberdade como valores éticos centrais, bem como promover a problematização dos desafios colocados à profissão por meio da leitura crítica da realidade concreta.

Trata-se de tarefa fundamental, pois com a clara ofensiva do pensamento único liberal, durante a década de 1990 e início do século XXI, que se acercaram também do Serviço Social, despontam tendências que reatualizam o conservadorismo, de modo que surge um novo irracionalismo via intervenções cada vez mais microscópicas e pontuais, tendências que incitam a razão instrumental, que se expressa em novas formas de empirismo, além das (falsas) tentativas de solução das demandas postas à profissão com as "novas metodologias”. A disputa - não só no Serviço Social, mas em toda sociedade - entre as tendências conservadoras e as tendências progressistas adota um novo perfil, em que o pensamento conservador assume um caráter renovado, forte, camuflado; não manifesta a sua verdadeira face, pois busca apropriar-se dos discursos progressistas - nos quais se inclui o desenvolvimento - renovando e recolocando nesses o seu conteúdo conservador.

Assim, urge o desafio teórico e também ético em assumir as tarefas impostas pelo tempo presente em termos de definições, especialmente relativo às singelas contribuições deste artigo ao novo-velho-desenvolvimento na nova conjuntura latino-americana do século XXI, assumindo a ineliminável postura de se manter vivo o pensamento crítico fundamentado na tradição marxista, no qual propomos o prisma da Teoria Marxista da Dependência.

Segue mais do que nunca vigente o desafio de casar a análise teórica da prática a uma intervenção organizada na própria realidade. Certamente, essa postura crítica não sairá da universidade brasileira, anestesiada que está com o "desenvolvimento" dos últimos anos. Sairá, sim, daqueles que têm sofrido os resultados perversos da política expansionista brasileira. Referimo-nos aos que sofrem com o transporte público a preço exorbitante, aos desalojados das 
áreas que darão lugar a suntuosos monumentos, e aos pobres e marginalizados que ficarão murados em suas favelas, mocambos e palafitas, para dar ao exterior a visão de um país sem pobreza.

Todos estes são componentes importantes que, mais que conclusões, motivam futuras pesquisas, práticas e questionamentos. É este objetivo, o de contribuir não apenas à crítica ao capitalismo dependente, mas também à sua superação, que visou este artigo.

\section{REFERÊNCIAS}

ABREU, Haroldo. Para além dos direitos: cidadania e hegemonia no mundo moderno. Rio de Janeiro: UFRJ, 2008.

BRASIL. Secretaria de Planejamento e Investimentos Estratégicos. Plano plurianual 2004-2007: mensagem presidencial. Brasília: MPOG, 2003. Disponível em: <http://www.sigplan.gov.br/arquivos/ portalppa/41_(menspresanexo).pdf>. Acesso em: 15 abr. 2009.

. Plano plurianual 2008-2011: mensagem presidencial. Brasília: MPOG, 2007. Disponível em: <http://www.sigplan.gov.br/download/avisos/001-mensagempresidencial_internet.pdf>. Acesso em: 15 abr. 2009.

. Plano plurianual 2012-2015; mensagem presidencial. Brasília: MPOG, 2012. Disponível em: <http://www.planejamento.gov.br/ secretarias/upload/Arquivos/spi/PPA/2012/mensagem_presidencial_ppa.pdf>. Acesso em: 11 mar. 2012.

CASTELO, Rodrigo. O novo-desenvolvimentismo e a decadência ideológica do estruturalismo latino-americano. In: CASTELO, Rodrigo. (Org.). Encruzilhadas da América Latina no século XXI. Rio de Janeiro: Pão e Rosas, 2010. p. 191-211.

FRANK, Gunder. America Latina: subdesarrollo o revolución. México: Ediciones Era, 1973.

FURTADO, Celso. O mito do desenvolvimento econômico. São Paulo: Círculo do Livro; Editora Paz e Terra, 1974.

LUKÁCS, George. Marx e o problema da decadência ideológica. In: COUTINHO, C. N. (Org.). Marxismo e teoria da literatura. Rio de Janeiro: Civilização Brasileira, 1968. p. 49-111.

MAGALHÃES, João Carlos. Ipea diz que 6,3 milhões deixaram po- 
breza de 2004 a 2009. Folha de São Paulo, São Paulo, 15 set. 2011. Disponível em: <http://www1.folha.uol.com.br/poder/975726-ipea-diz-que-63-milhoes-deixaram-pobreza-de-2004-a-2009.shtml>. Acesso em: 15 set. 2011.

MARINI, Ruy Mauro. Dialética da dependência. In: TRASPADINI, Roberta; STÉDILE, João Pedro (Orgs). Ruy Mauro Marini: vida e obra. São Paulo: Expressão Popular, 2005.

- As razões do neodesenvolvimentismo (resposta a Fernando Henrique Cardoso e a José Serra). In: . Dialética da dependência: uma antologia da obra de Ruy Mauro Marini. Organização e apresentação de Emir Sader. Petrópolis: Vozes, 2000. p. 167-241.

MARX, Karl. O capital: crítica da economia política: O Processo de produção de capital. São Paulo: Abril Cultural, 1984. (v. 1, tomos 1 e 2). PRADO JR., Caio. A Revolução brasileira. São Paulo: Brasiliense, 1966. RENDA cresceu $28 \%$ e desigualdade caiu 5,6\%, aponta Ipea. Folha de São Paulo, São Paulo, 15 set. 2011. Disponível em: <http://www1. folha.uol.com.br/poder/975674-renda-cresceu-28-e-desigualdade-caiu-56-aponta-ipea.shtml>. Acesso em: 15 set. 2011.

SICSÚ, João; DE PAULA, Luiz Fernando; MICHEL, Renaut. Por que novo desenvolvimentismo? Revista de Economia Política, v. 27, n. 4, p. 507-524, dez. 2007. Disponível em: <http://www.scielo.br/pdf/ rep/v27n4/a01v27n4.pdf>. Acesso em: 18 set. 2008. 